\title{
Evaluation of the Prevalence of Rheumatoid Factor in Five Regions of Cameroon
}

\author{
Etienne Philemon ATABONKENG,${ }^{1}$ Dieudonné ADIOGO, ${ }^{2}$ Essono Mvoa EMMANUEL, ${ }^{3}$ Ouambo Fotso HERVÉ, ${ }^{1}$ \\ Appolonie MANGA OWONO, ${ }^{3}$ Marie Claire OKOMO ASSOUMOU ${ }^{3}$ \\ ${ }^{1}$ Department of Microbiology, Catholic University of Central Africa, Yaoundé, Cameroon \\ ${ }^{2}$ University of Douala, Faculty of Pharmacology, Douala, Cameroon \\ ${ }^{3}$ University of Yaounde I, Faculty of Medicine and Biomedical Sciences, Yaoundé, Cameroon
}

\begin{abstract}
Objectives: This study aims to assess the prevalence of rheumatoid factor (RF) of immunoglobulin M nature in the Cameroonian population and the influence of demographic factors on its production.

Patients and methods: A total of 369 subjects ( 125 males and 244 females; mean age $42.36 \pm 15.73$ years; range $15-88$ years) were tested from five regions of Cameroon (Center, East, Far North, Littoral and West) between July 2012 and December 2012. Whole blood was collected from each participant and the serum was used for immunoglobulin M RF assay using the RF-IMMESCO test (agglutination technique).

Results: The prevalence of RF in the whole population was $5.4 \%$, with a female to male ratio of 2.4. RF was present in all age groups, but especially in participants of 30 to 60 years of age. The Center region had the highest prevalence (7.5\%), while the West region had the lowest prevalence (2.2\%). However, there was no significant difference between studied regions ( $p>0.05)$. Of the 369 participants tested, 257 (69.6\%) complained of having suffered joint pain at one time or another while 112 did not complain of joint pain. The prevalence of RF was $6.22 \%$ in the former group and $3.57 \%$ in the latter. Among those 50 to 70 years of age, nearly $90 \%$ had at least one painful joint.

Conclusion: The presence of RF in the study population may lead to joint diseases, which are more common disabling diseases among the inhabitants of Cameroon. Further studies are needed to bring more insight on the prevalence of RF in Cameroon.

Keywords: Autoimmune diseases; prevalence; rheumatoid factor.
\end{abstract}

Rheumatoid factor (RF) is an antibody against human or animal immunoglobulin (Ig) and most often belonging to the IgM class. RF may also be of IgA, IgG or IgE isotype. ${ }^{1,2}$ Whatever the Ig class of these factors, their common denominator is that they are always directed against human or anim al IgG. Some RF can autoagglutinate to form polymers comprising many identical molecules. The valence of an IgM molecule is 10; an RF binds to $10 \mathrm{IgG}$ molecules and thus forms a macromolecular complex. ${ }^{3}$ These immune complexes are responsible for inflammation, which is triggered by their accumulation on tissues. Complement fixation on immune complexes plays a role in the genesis of tissue damage. ${ }^{4}$ Phagocytosis by polymorphonuclear immune complexes releases various lysosomal enzymes, free radicals, and derivatives of arachidonic acid that induce inflammation in the articulation. ${ }^{4}$ This can lead to rheumatoid arthritis (RA) which may be diagnosed by assessing changes in biochemical factors, such as RF. However, the presence of significant levels of RF at the beginning of $R A$ is an indicator of poor prognosis. ${ }^{5}$

The specificity of these factors is very variable and its heterogenicity is large. RF can be found in many other pathological conditions, certain 
connective tissues, Sjögren's syndrome where the levels of RF are particularly high, infectious diseases (transient presence) and normal subjects. ${ }^{6}$ RF may be present in the serum of some patients without any clinical manifestation, even for several years before the onset of rheumatoid polyarthritis (RP). However, RF may be detected in patients who never develop RP.7 At the active phase, RF is present in $70-85 \%$ of positive RP patients, which corresponds to "seropositive" RP as opposed to "seronegative" RP in which there is no detectable $\mathrm{RF}$. Severe RP with extra-articular manifestations are almost always strongly "seropositive".

In Cameroon, people frequently complain of joint diseases which may be chronic and disabling disorders that affect the quality of life. ${ }^{8,9} \mathrm{RF}$ is so far the main biomarker sought locally for the diagnosis of rheumatic diseases. With this in mind, in this study, we aimed to assess the prevalence of $\mathrm{RF}$ of IgM nature in the Cameroonian population and the influence of demographic factors on its production, as the significance of autoantibodies such as RF in the diagnosis and monitoring of some autoimmune diseases is well-known.

\section{PATIENTS AND METHODS}

This prospective, cross-sectional and descriptivebased study was conducted between July 2012 and December 2012 in five regions of Cameroon (the Center, East, Far North, Littoral and West regions). The studied regions were chosen by convenience sampling technique. These regions are characterized by diverse climatic conditions and cultural habits. A total of 369 participants (125 males, 244 females; mean age $42.36 \pm 15.73$ years; range 15 to 88 years) who were accompanying patients were recruited consecutively in the major health facilities of the five regions. Each participant was asked to sign an informed consent form, and then complete a questionnaire on demographic data. In the same questionnaire, the participants were also asked whether they were suffering or had ever suffered from joint pain for more than six weeks. About $5 \mathrm{~mL}$ of blood was thereafter collected by venipuncture, and used for the preparation of serum. The serum was aliquoted and stored at $-20{ }^{\circ} \mathrm{C}$ for analyses. The study protocol was validated by the Cameroon National Ethics Committee for Human Health Research (authorization N016/CNE/SE/2012).
Serological analyses were performed at the Center for the Study and Control of Communicable Diseases, Faculty of Medicine and Biomedical Sciences in Yaoundé.

We tested the serum of each participant for IgM-RF using the IMMESCO-RF kit (INMESCO GmbH-Neustadt//Wied, Germany) according to the principle of Waaler Rose technique. Briefly, $50 \mu \mathrm{l}$ of serum and $50 \mu \mathrm{l}$ of reagent IMMESCO$\mathrm{RF}$ were placed in a circle of the test plate provided by the manufacturer. Reagents and serum samples were stirred with a spatula and mixed by rotating the plate for two minutes, using a mechanical homogenizer. The development of visible agglutination reflected the presence of $\mathrm{RF}$ $\geq 8 \mathrm{IU} / \mathrm{mL}$ in the analyzed serum, while absence of agglutination was considered to be a negative result. The assay was validated using positive and negative controls provided by the manufacturer of the kit.

\section{Statistical analysis}

Statistical analyses were performed using SPSS for Windows version 16.0 and R 2.13 .1 software programs (SPSS Inc., Chicago, IL, USA). Fisher's exact tests were used for comparison of proportions. A level of $p<0.05$ was used to indicate statistical significance.

\section{RESULTS}

The greatest number of participants was recruited in the Center region $(\mathrm{n}=161,47 \%)$, while the smallest number of subjects was from the Littoral region ( $\mathrm{n}=29,8 \%)$ (Figure 1). From the 369 participants recruited, 257 (69.6\%) reported to be suffering or had suffered from joint pain lasting for more than six months. These included 181 females and 76 males, indicating a female/male ratio of 2.4. From the age of 15 to 88 years, the percentage of participants complaining of joint pain was increasing (Figure 2); however, it was around 30 years of age that these pains started to become very frequent and the number of people suffering from pain gradually increased. Between 50 and 70 years of age, nearly $90 \%$ of the study population had at least one painful joint (Figure 2). The distribution of the most painful joints among the studied population is shown in Figure 3, indicating that the cervical vertebrae and knees were the most affected joints. 


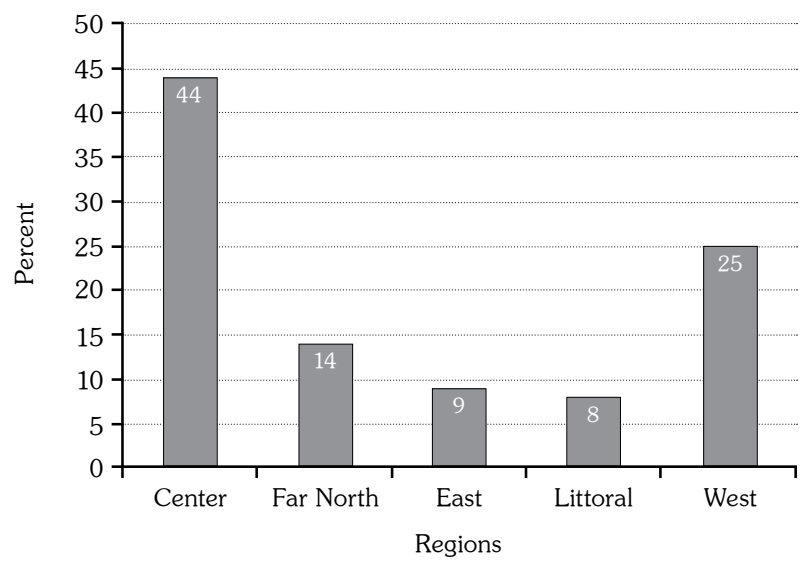

Figure 1. Participants in five regions of study.

Of 369 samples analyzed, 20 were positive for $\mathrm{RF}$, representing a prevalence of $5.4 \%$. The $\mathrm{RF}$ concentration ranged from $16 \mathrm{IU} / \mathrm{mL}$ to $512 \mathrm{IU} / \mathrm{mL}$. Fourteen females (5.74\%) and six males $(4.8 \%)$ were positive for $\mathrm{RF}$, and this represented a female/male ratio of 2.4 (Figure 4). However, there was no significant difference in the production of RF between males and females $(p=0.81)$. The prevalence of $\mathrm{RF}$ was different according to age groups, as shown in Table 1 . RF were absent among the 23 participants aged $\geq 69$ years, but the statistical analyses (95\% confidence interval) showed no significant difference between age groups $(p=0.92)$. Likewise, the prevalence of RF showed no significant difference between the five different regions ( $p>0.05)$ (Table 2). Of the 257 participants who reported having joint pain, 16 were positive for RF. This corresponded to the RF prevalence of $6.22 \%$ in the group of participants that suffered from joint pains, while only $3.57 \%$ of the participants who had never felt

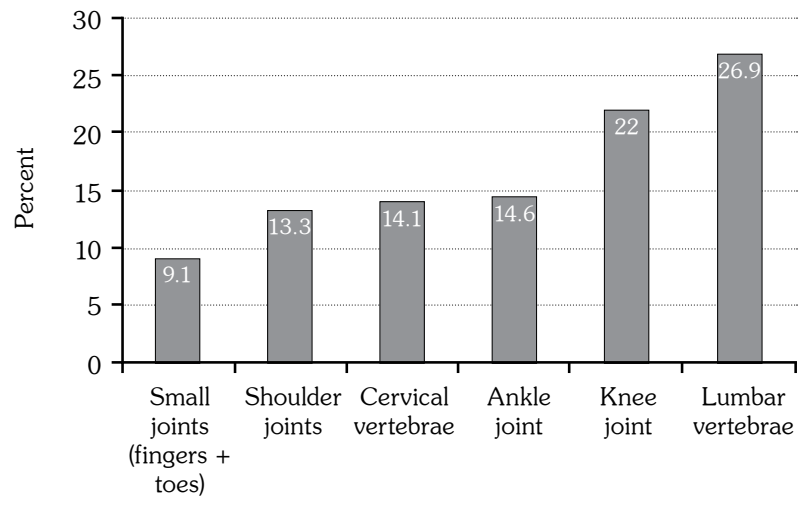

Figure 3. Painful joints reported by participants.

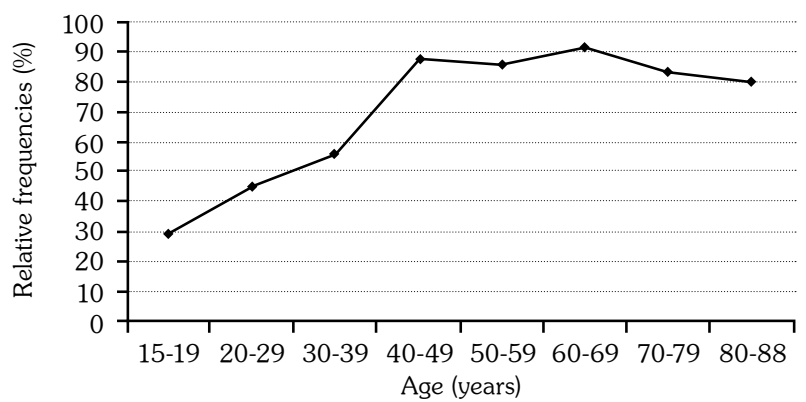

Figure 2. Evolution of joints pain amongst participants according to age.

joint pain were tested positive for RF. However, the difference in frequency of RF detection between the two groups remained statistically nonsignificant ( $p>0.05$, Fisher's exact test).

\section{DISCUSSION}

The prevalence of RF in the studied population was $5.4 \%$. RF stimulates the immune system in a continuous manner, resulting in a high frequency of autoimmune diseases including RP diseases. ${ }^{10}$ A similar study in a malaria-endemic area in Cóte d'Ivoire ${ }^{11}$ carried out in 1999 showed an RF prevalence of $7 \%$ among people aged between 03 and 70 years. The current study did not include subjects younger than 15 years of age, and this may be the reason why the prevalence reported here is slightly different from the one reported in the Cóte d'Ivoire study. A different study in the African population revealed that $16 \%$ of the healthy population was positive for $\mathrm{RF} ;{ }^{11}$ the presence of elevated background levels of IgM-RF in African controls $(16 \%$ of IgM-RF positive healthy controls when using the recommended

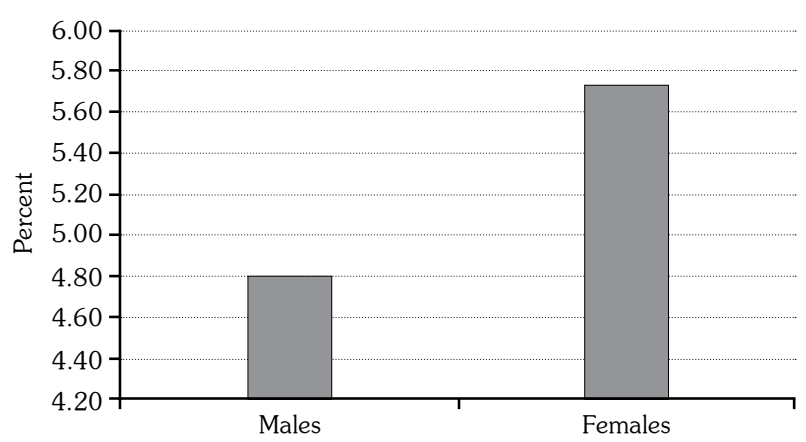

Figure 4. Prevalence of rheumatoid factor among male and female participants. 
Table 1. Prevalence of rheumatoid factor according to age groups

\begin{tabular}{|c|c|c|c|c|c|c|c|c|c|c|c|c|c|c|c|c|c|c|c|c|c|c|c|}
\hline & $\mathrm{n}$ & $\%$ & Range & $\mathrm{n}$ & $\%$ & Range & $\mathrm{n}$ & $\%$ & Range & $\mathrm{n}$ & $\%$ & Range & $\mathrm{n}$ & $\%$ & Range & $\mathrm{n}$ & $\%$ & Range & $\mathrm{n}$ & $\%$ & Range & $\mathrm{n} \%$ & Range \\
\hline Age (years) & & & $15-19$ & & & $20-29$ & & & 30-39 & & & $40-49$ & & & $50-59$ & & & 60-69 & & & 70-79 & & $80-88$ \\
\hline $\begin{array}{l}\text { Number of } \\
\text { participants } \\
\text { Positive rheumatoid }\end{array}$ & 17 & 4.6 & & 78 & 21.1 & & 68 & 18.4 & & 86 & 23.3 & & 62 & 16.8 & & 35 & 9.5 & & 18 & 4.9 & & $\begin{array}{ll}51.4 \\
\end{array}$ & \\
\hline factor & & 11.7 & & & 2.6 & & & 7.3 & & & 4.6 & & & 8.1 & & & 5.7 & & & 0 & & 0 & \\
\hline
\end{tabular}

Table 2. Prevalence of rheumatoid factor in studied regions

\begin{tabular}{|c|c|c|c|c|c|c|c|c|c|c|}
\hline \multirow[t]{2}{*}{ Region } & \multicolumn{2}{|c|}{ Center } & \multicolumn{2}{|c|}{ East } & \multicolumn{2}{|c|}{ Far North } & \multicolumn{2}{|c|}{ Littoral } & \multicolumn{2}{|c|}{ West } \\
\hline & $\mathrm{n}$ & $\%$ & $\mathrm{n}$ & $\%$ & $\mathrm{n}$ & $\%$ & $\mathrm{n}$ & $\%$ & $\mathrm{n}$ & $\%$ \\
\hline Number of participants & 161 & & 35 & & 51 & & 29 & & 93 & \\
\hline Frequency of positive & 12 & 7.5 & 2 & 5.7 & 3 & 5.9 & 1 & 3.4 & 2 & 2.2 \\
\hline
\end{tabular}

cut-off values) is probably caused by non-specific activation of the immune system by different infectious and parasitic diseases, ${ }^{11}$ which constitute the main burden in Africa. Indeed, people younger than 15 years of age who were more exposed to parasitic and infectious diseases were also included in the study. Differences between the two studies may also be attributed to the use of two distinct analysis methods (ELISA method for titration of IgM-RF in the previous study, and an agglutination method for detection of RF in the current study) which have different sensitivities.

Our data showed that females produced more RF than males (16 females as compared to 4 males) with a 2.4 -fold increased risk in females close to 2.61 obtained in Cóte d'Ivoire ${ }^{12}$ although the difference was not statistically significant ( $p>0.05$ ). This can easily be explained by the influence of female sex hormones on autoimmune processes, as reported earlier. ${ }^{13}$ Female hormones have a certain role in the onset and/or worsening of the disease, as evidenced by the risk of flare induced by estrogen-progestogen pills, pregnancy, and the postpartum period. ${ }^{13}$

Participants affected by joint pains had a high prevalence of RF as compared to those not affected; but the difference was not statistically significant between these two groups ( $p>0.05$ ). On the other hand, previous investigations showed that the prevalence of RF can be up to $70 \%$ amongst patients with $\mathrm{RA}$, whereas the prevalence reported in Cameroon during this study was $6.22 \%$ amongst participants suffering from joint pain only. The current study did not include only RA patients. There are indeed degenerative joints pain diseases such as osteoarthritis, metabolic arthropathies such as gout, and autoimmune arthropathies such as lupus erythematosus, in which RF may not be involved. ${ }^{14}$ Some neurologic disorders may also be associated with joint pain.

Rheumatoid factor was present in people aged 15-69 years and absent beyond 69 years. Some studies have shown that several autoimmune diseases, including RP can occur at any age but mostly between 40 and 60 years. Beyond this age, the rate decreases gradually. ${ }^{5}$ The studies of RF conducted in subjects $>65$ years of age revealed that clinical significance of autoantibodies in elderly patients is related more to global health status than to the effects of aging. ${ }^{15,16}$ Some studies claim that the incidence of RF increases with age and that about $20 \%$ of people over 65 have an elevated RF. ${ }^{17}$ Investigations in the Japanese population also revealed a significant positive correlation between age and RF values. ${ }^{18}$ However, other studies showed that RF levels seemed to be similar from 20 to 100 years of age. ${ }^{19}$ These studies show variability in the correlation between age and RF. It is important to emphasize the fact that aging is accompanied by decreased immunity, alteration of $\mathrm{T}$ lymphocyte cooperation with B-lymphocytes, decreased B-cell renewal and alteration of costimulatory pathways. ${ }^{20}$ This set of phenomena associated with age may explain the absence of RF beyond 69 years of age as observed in some studies. ${ }^{20}$ The method we used (agglutination technique) is not as sensitive as the ELISA method and the small size of our sample may also explain why we did not obtain positive sample above the age of 65 years. 
We did not notice any significant difference of RF prevalence between participants from the Center region and those from the West region $7.5 \%$ and $2.2 \%$ of RF-positive, respectively; $p>0.05$ ), and this may mean that RF production is not influenced by climate. The lack of a significant difference in the prevalence of RF between the different regions of Cameroon is in agreement with the results obtained by Klemmer et al. ${ }^{13}$ in 2005 , who noticed that environmental factors do not seem to have a major influence on the activity of RF.

\section{Conclusion}

The prevalence of IgM-RF was $5.4 \%$ in our study population, and females produced 2.4 times more RF than males. Production of RF was not influenced by age or environmental factors. RF prevalence in participants affected by joint pain that lasted for six weeks and above was higher than those who had never felt joint pain. This preliminary study provides information on RF prevalence in Cameroon's population, in relation with joint pains as well as the relationship between aging and RF. Further studies with larger sample size and also focusing on the impact of bacterial, parasitic and viral etiologies, etc. are needed to bring more insight on the prevalence of RF in Cameroon.

\section{Declaration of conflicting interests}

The authors declared no conflicts of interest with respect to the authorship and/or publication of this article.

\section{Funding}

The authors received no financial support for the research and/or authorship of this article.

\section{REFERENCES}

1. Bonnotte B. Pathogenic mechanisms of autoimmune diseases. Rev Med Interne 2010;31:292-5.

2. Sany J. La polyarthrite rhumatoïde de l'adulte. John Libbey Eurotext Ed 2003. p. 298.

3. Preud'homme JL, Clot J, Pasquali Jl, Youinou P, Saraux A. Autoimmunité et Autoanticorps. Cahier de Formation 1999. p. 1-24.

4. Kereveur A, Myara I. Physiopathologie des immunscomplexes circulants. Eurobiologiste 1995;29:51-8.

5. Morel J, Combe B. How to predict prognosis in early rheumatoid arthritis. Best Pract Res Clin Rheumatol
2005; 19:137-46.

6. Dayer E, Consilia S, Buchard PA, Suva S. Ac anti-peptide cyclique citrulliné (CCP) et Polyarthrite rhumatoïde. Caduceus Express 2004;6. Available from: https://web2.hopitalvs.ch/fr/ichv/ DocumentationDoc/2004_02_Anti\%20CCP_ED_F. pdf

7. Skare TL, Silva BG, Gomes D, Gomes F, Rumor C, Giacomini G. Rheumatoid factor and tobacco exposure. Braz Arch Biol Technol 2002;45:203-7.

8. Jeandel P, Chouc PY, Laroche R. Rhumatologie en Afrique Noire: Certitudes, Perspectives et Inconnues. Médecine d'Afrique Noire 1991;38:53-61.

9. Arnett FC, Edworthy SM, Bloch DA, McShane DJ, Fries JF, Cooper NS, et al. The American Rheumatism Association 1987 revised criteria for the classification of rheumatoid arthritis. Arthritis Rheum 1988;31:315-24.

10. Nielsen SF, Bojesen SE, Schnohr P, Nordestgaard BG. Elevated rheumatoid factor and long term risk of rheumatoid arthritis: a prospective cohort study. BMJ 2012;345:5244.

11. Viatte S, Flynn E, Lunt M, Barnes J, Singwe-Ngandeu $\mathrm{M}$, Bas S, et al. Investigation of Caucasian rheumatoid arthritis susceptibility loci in African patients with the same disease. Arthritis Res Ther 2012;14:239.

12. Devouassoux G. Physiologie des Hypersensibilités de type III-Immunologie et Mécanismes Immunopathologiques. CHLS \& INSERM 2010:23:3-5.

13. Klemmer N, Vittecoq O. Polyarthrite rhumatoïde et facteurs environnementaux. La Lettre du Rhumatologue 2004;307:4.

14. Andrade F, Darrah E, Rosen A. Autoantibiodies in rheumatoid arthritis. In: Firestein GS, Budd RC, Gabriel SE, editors. Kelley's Textbook of Rheumatology. Chap 56. 9th ed. Philadelphia: Saunders Elsevier; 2012. p. 3-7.

15. Juby AG, Davis P. Prevalence and disease associations of certain autoantibodies in elderly patients. Clin Invest Med 1998:21:4-11.

16. Önen F, Türkay C, Meydan A, Dökmetaş HS, Sümer $\mathrm{H}$, Hocaoğlu L, et al. Prevalence of Rheumatoid Factor (RF) and Anti-native-DNA Antibodies (anti-n DNA) in Different Age Subpopulations. Tr. J. of Medical Sciences 1998;28:85-8.

17. Cush JJ, Weinblatt ME, Kavanaugh A. Rheumatoid Arthritis: Early Diagnosis and Treatment. 3rd ed. New York: Professional Communications; 2010.

18. Hayahara C, Ikeda K, Sakanishi Y, Ota T. Incidence of serum rheumatoid factors in elder non-rheumatic individuals. Rinsho Byori 2010;58:211-5.

19. Gaston JSH. Rheumatic diseases-immunological mechanisms and prospects for new therapies. Cambridge: Cambridge University Press; 1999.

20. Menzel EJ, Zlabinger GJ, Dunky A, Steffen C. Autoimmunity and T-cell subpopulations in old age. Arch Gerontol Geriatr 1988;7:249-60. 